\title{
Sistem Deteksi Dini Bencana Banjir Menggunakan Modul 433MHz Berbasis Arduino
}

\author{
M. Zainal Arifin*, Ema Utami, Eko Pramono \\ Program Studi Megister Teknik Informatika, Universitas Amikom Yogyakarta \\ *Email: zainal.arifin@students.amikom.ac.id
}

\begin{tabular}{|c|c|}
\hline Info Artikel & Abstrak \\
\hline $\begin{array}{l}\text { Kata Kunci : } \\
\text { RF 433MHz, banjir, arduino, deteksi } \\
\text { dini } \\
\text { Keywords : } \\
\text { RF 433MHz, flood, arduino, early } \\
\text { detection } \\
\text { Tanggal Artikel } \\
\text { Dikirim : } 17 \text { Januari } 2020 \\
\text { Direvisi : } 20 \text { Februari } 2020 \\
\text { Diterima : } 2 \text { Maret } 2020\end{array}$ & $\begin{array}{l}\text { Banjir adalah bencanan alam yang sulit di deteksi kapan akan datang terutama } \\
\text { di musim hujan. Akibatnya banyak masyarakat yang kehilangan harta benda } \\
\text { bahkan terkadang sampai menimbulkan korban jiwa akibat bencana banjir. } \\
\text { Untuk itu, estimasi level ketinggian air penting untuk menentukan bahaya } \\
\text { mendasar dalam resiko datangnya banjir. Objek pengukuran yang digunakan } \\
\text { dalam penelitian ini yaitu Tinggi Muka Air (TMA) dengan menggunakan teknik } \\
\text { pesan singkat yang bisa dikirim melalui gelombang radio dan sensor } \\
\text { ketinggian air sungai sebagai sensor yang mengambil nilai ketinggian air } \\
\text { sungai itu sendiri, sehingga tidak membutuhkan sinyal dan jaringan internet } \\
\text { serta tidak membutuhkan pulsa untuk penggunaannya. hasil akhir dari } \\
\text { penelitian ini adalah informasi ketinggian air yaitu status normal, siaga I, siaga } \\
\text { II, siaga III atau siaga IV, dan juga hasil pengujian kinerja sistem dengan } \\
\text { variabel pengukuran jarak, waktu, dan packet loss dalam jangka waktu } \\
\text { pengukuran } 5 \text { menit. } \\
\text { Abstarct } \\
\text { Flooding is a difficult natural disaster in the detection of when it will come } \\
\text { especially in the rainy season. As a result many people lose property even } \\
\text { sometimes to inflict casualties due to flood disasters. Therefore, estimation of } \\
\text { water level is important to determine the fundamental danger in the risk of } \\
\text { flooding. The measuring object used in this study is water advance (TMA) } \\
\text { using a short message technique that can be sent through radio waves and } \\
\text { river water altitude sensors as a sensor that takes the river water's altitude } \\
\text { value. itself, so it does not require any signal and Internet network and does } \\
\text { not require credit for its use. The final result of the study is water elevation } \\
\text { information i.e. normal status, Standby I, Standby II, standby III or Standby } \\
\text { IV, and also the results of system performance testing with variable distance, } \\
\text { time measurement and loss packet within a } 5 \text { minute measurement period. }\end{array}$ \\
\hline
\end{tabular}

\section{PENDAHULUAN}

Banjir adalah suatu kondisi dimana terjadi peningkatan debit air sungai sehingga meluap dan menggenangi daerah sekitarnya, dan menyebabkan berbagai kerugian bagi masyarakat yang terkena bencana ini [1]. Penelitian Achmad Muzakky dkk pada tahun 2018 yang berisi tentang monitoring level air dengan level yang di informasikan adalah aman, siaga, awas dengan menggunakan water level sensor sebagai sensor untuk mendapatkan level ketinggian air dan NodeMCU ESP8266 sebagai pemroses dan dan mengirimkan data secara nirkabel ke smartphone android menggunakan aplikasi BLYNK. Berdasarkan penelitian yang dilakukan hasil dari pengujiannya menuliskan respon dari alat dan sistem yang dibuat rata rata-rata respon aplikasi terhadap keadaan sebenarnya kurang dari 2 detik. Dan dalam kesimpulannya menuliskan bahwa informasi dapat di akses dengan syarat mendapat akses internet [2]. Penelitian Dedi Satria dkk pada tahun 2017 yang berisi tentang sistem pendeteksi dini bencana banjir dengan dengan informasi peringatan berbasis sms gateway, menggunakan sensor ultrasonic sebagai sensor untuk membaca level ketinggian air, Arduino uno sebagai mikrokontroller yang digunakan untuk memproses 
data dan modem gsm wavecom untuk output pengiriman informasi melalui sms yang dikirimkan ke masyarakat [3]. Teknik pengiriman pada pendeteksi banjir berbasis SMS (Short Message Service) dengan menggunakan teknik pengiriman ini memiliki kelemahan yaitu pada penggunaan pulsa dan jaringan isp yang digunakan [4]. Pada penelitian yang dilakukan dengan menggunakan RF 433MHz diharapkan bisa menyelesaikan masalah pulsa dan jaringan internet [5], karena modul RF tidak membutuhkan sinyal dan jaringan serta tidak membutuhkan pulsa untuk penggunaannya sehingga dapat memberi informasi dini bencana banjir kepada instansi yang bertugas secara efektif dan maksimal.

Metode pengukuran ketinggian air sungai menggunakan sensor water leve/sederhana dalam penggunaannya. cara kerja dari sensor ini yaitu apabila sensor water level 1 terendam air yang artinya nilai dari pin level 1 pada Arduino bernilai 0 , maka arduino nano membaca air berada pada ketinggian level 1 . Selanjutnya apabila sensor water leve/2 terendam air maka Arduino membaca air pada ketinggian level 2. Untuk level 3 dan 4 cara kerjanya sama. Pada penelitian yang dilakukan dengan menggunakan RF 433MHz diharapkan bisa menyelesaikan masalah pulsa dan jaringan internet [5], karena modul RF tidak membutuhkan sinyal dan jaringan serta tidak membutuhkan pulsa untuk penggunaannya sehingga dapat memberi informasi dini bencana banjir kepada instansi yang bertugas secara efektif dan maksimal.

\section{METODE PENELITIAN}

\subsection{Jenis dan Pendekatan Penelitian}

Jenis dan pendekatan penelitian yang dilakukan adalah sebagai berikut: 1. Jenis Penelitian Eksperimen

Penelitian ini merupakan penelitian eksperimen yaitu: meneliti dan menerapkan atau mengimplementasikan pengiriman informasi menggunakan modul RF $433 \mathrm{MHz}$ pada pendeteksi dini bencana banjir dan menguji performanya.

\section{Pendekatan Penelitan Kuantitatif}

Pada penelitian ini menggunakan pendekatan kuantitatif, hasil dari penelitian ini merupakan informasi berupa angka dari hasil pengujian dan eksperimen yang dilakukan oleh peneliti. Pengumpulan data dilakukan melalui hasil pengujian dan eksperimen yang kemudian data tersebut menjadi hasil dari pengujian berupa jarak, waktu, dan packet loss.

\subsection{Metode Pengumpulan Data}

Metode pengumpulan data menggunakan metode eksperimen. Data-data yang dikumpulkan dari hasil eksperimen adalah:

a. Waktu pengiriman

b. Jarak pengiriman

c. Packet loss dalam waktu tertentu.

\subsection{Alur Penelitian}

Bagian ini berisi diagram alur langkah penelitian secara lengkap dan terinci termasuk di dalamnya tercermin algoritma, rute, pemodelan-pemodelan, desain, yang terkait dengan aspek perancangan sistem. Alur penelitian eksperimen pada penelitian ini ditunjukkan pada gambar 1. 


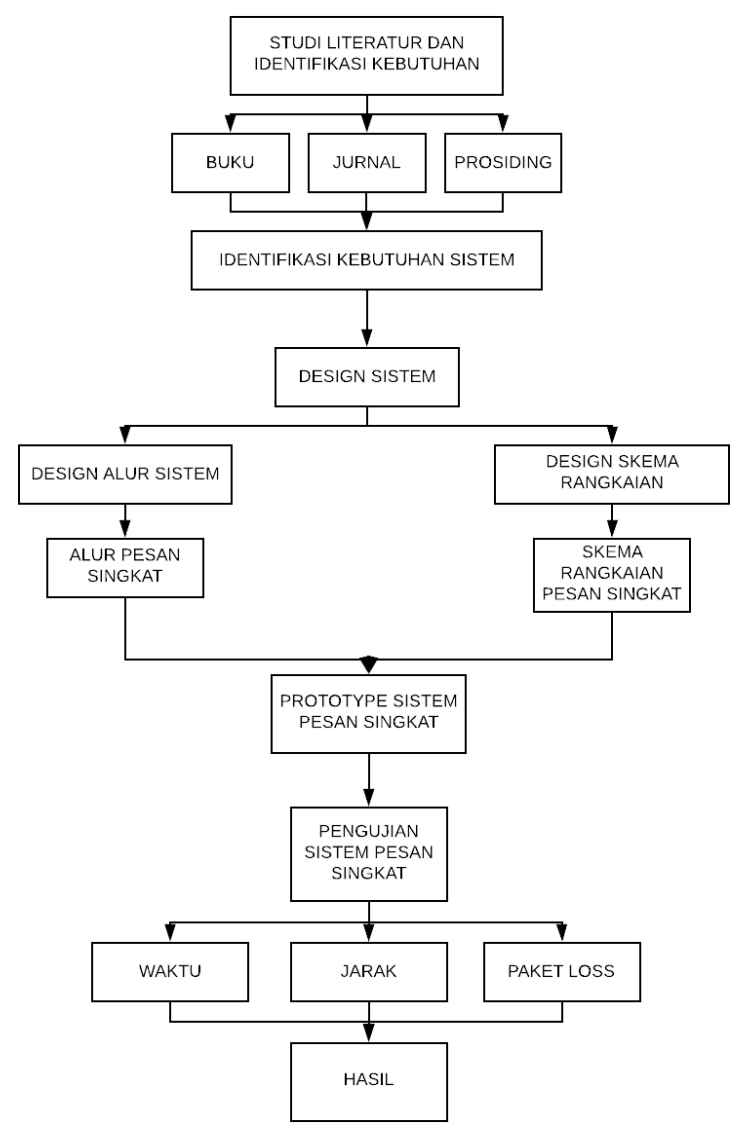

Gambar 1. Alur penelitian

Pada gambar 1 adalah flowchart atau alur penelitian yang akan dilakukan pada penelitian ini, yaitu tahap pertama melakukan studi literatur dan identifikasi kebutuhan dari system yang akan dibuat, selanjutnya membuat design atau rancangan system, selanjutnya membuat prototype system, selanjutnya melakukan pengujian dan pengambilan data pengujian, selanjutnya membuat dokumentasi dan laporan penelitian.

\subsection{Design sistem}

Pada tahapan design sistem rencana sistem akan dibuat sesuai dengan design pada gambar 2.

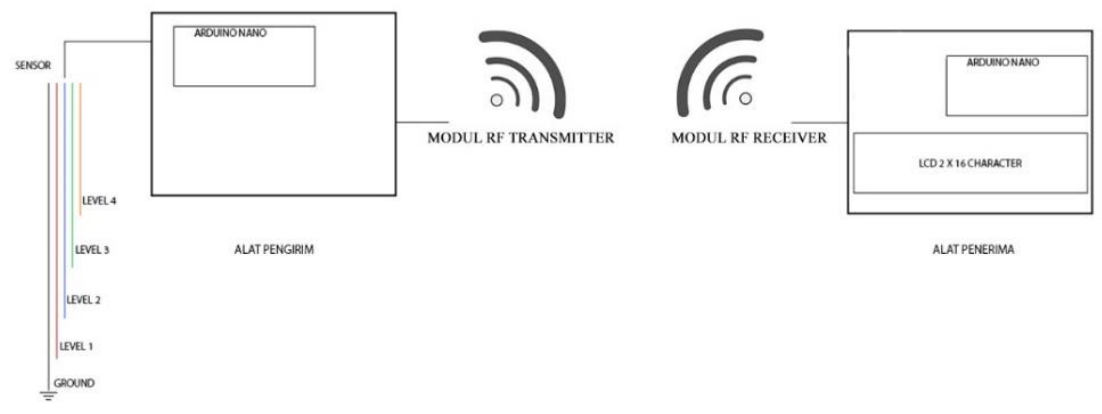

Gambar 2. Design sistem menggunakan teknit pengiriman pesan singkat

Pada gambar 2, sistem dibagi menjadi 2 alat yaitu alat pengirim (transmitter) dan alat penerima (receiver). Bagian design alat pengirim komponen dan rangkaian ada pada gambar 3 , dan bagian alat penerima ada pada gambar 4 . 


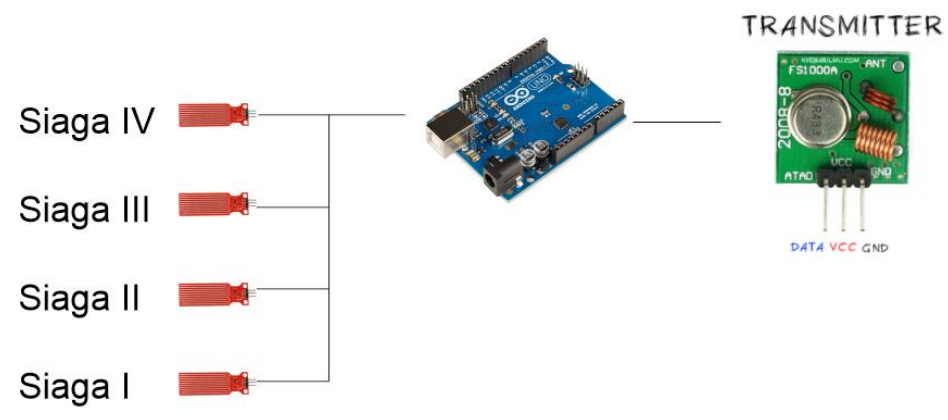

Gambar 3. rangkaian sistem menggunakan teknit pengiriman pesan singkat bagian transmitter

Pada gambar 3, komponen yang digunakan untuk membuat alat pengirim adalah sensor water level, Arduino uno, dan modul transmitterRF $433 \mathrm{MHz}$.

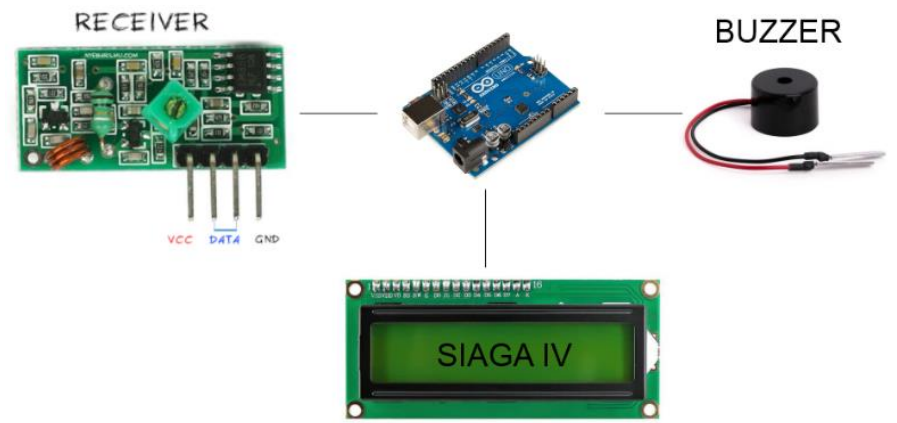

Gambar 4. rangkaian sistem menggunakan teknit pengiriman pesan singkat bagian receiver

Pada gambar 4, komponen yagn digunakan untuk membuat alat penerima informasi adalah modul receiver RF $433 \mathrm{MHz}$, Arduino uno, LCD 2x16 karakter, dan buzzer sebagai notifikasi apabila level ketinggian air "siaga IV".

\subsection{Perancangan sistem}

Pada tahapan perancangan, sistem akan dibuat seperti pada flowchart pada gambar 5 dan gambar 6 untuk prototype sistem.

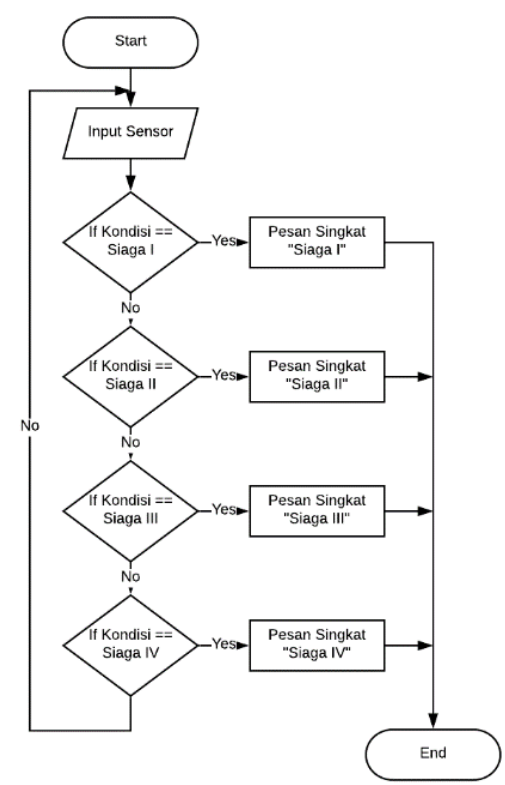

Gambar 5 . Flowchart alat pengirim 
Pada gambar 5 merupakan flowchar proses dari rangkaian pengirim. Apabila input sensor 1 terendam air maka alat pengirim mengirimkan informasi "siaga I" melalui moduk RF 433MHz. apabila kondisi tidak ada input maka akan kembali ke proses membaca input, maka alat pengirim tidak akan mengirim informasi apapun.

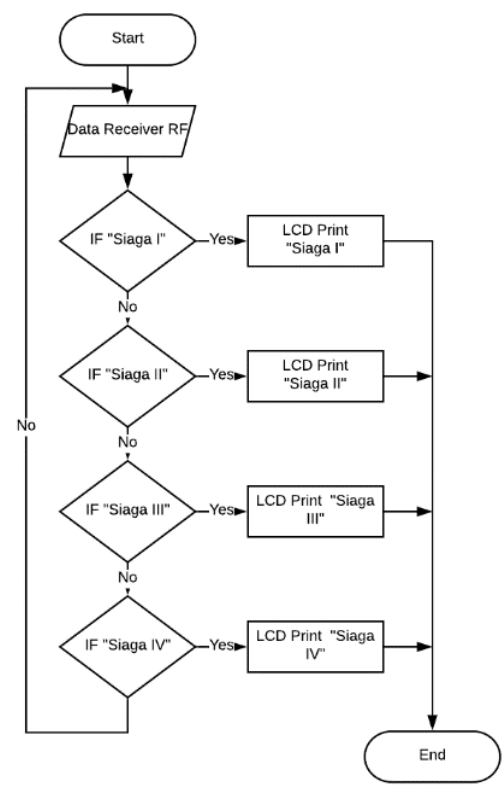

Gambar 6. Flowchart alat penerima

Pada gambar 6 adalah gamba flowchar dari alat penerima, apabila dari modul receivermenerima informasi "siaga I" maka akan di proses dan menampilkan tulisan "siaga I" pada LCD, dan apabila alat penerima menerima informasi "siaga IV" akan menampilkan tulisan di LCD dan membunyikan buzzer peringatan.

\section{HASIL DAN PEMBAHASAN}

\subsection{Landasan teori}

Modul RF 433 ini harganya cukup terjangkau sehingga cocok untuk digunakan untuk komunikasi menggunakan frekuensi radio (RF). Hal yang perlu diperhatikan jika menggunakan modul ini adalah kerentanannya terhadap noise yang dapat mengganggu komunikasi. Gambar 7 merupakan bentuk fisik modul RF 433. Adapun spesifikasi modul dapat dilihat di Tabel 1 dan 2.

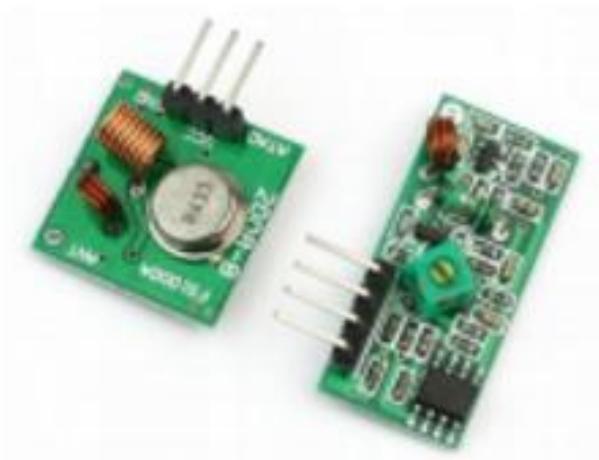

Gambar 7. Modul RF 433MHz

104 | IJAI (Indonesian Journal of Applied Informatics) 
Table 1. Spesifikasi Modul RF 433MHz Transmitter

\begin{tabular}{ll}
\hline Model & MX-FS-03V \\
\hline Tegangan & $3.5 \mathrm{~V}$ \\
\hline Ukuran & $19 \times 19 \mathrm{~mm}$ \\
\hline Mode kerja & $\mathrm{AM}$ \\
\hline Kecepatan transmisi & $4 \mathrm{~kb} / \mathrm{s}$ \\
\hline Daya transmisi & $10 \mathrm{mw}$ \\
\hline Frekuensi & $433 \mathrm{MHz}$ \\
\hline Antenna & $25 \mathrm{~cm}$ \\
\hline Pin & Data, VCC, GND \\
\hline
\end{tabular}

Table 2. Spesifikasi Modul RF 433MHz Receiver

\begin{tabular}{ll}
\hline Model & MX-05V \\
\hline Tegangan & $5 \mathrm{~V}$ \\
\hline Ukuran & $30 \times 14 \mathrm{~mm}$ \\
\hline Frekuensi & $433.92 \mathrm{MHz}$ \\
\hline Arus & $4 \mathrm{~mA}$ \\
\hline Antenna & $32 \mathrm{~cm}$ \\
\hline Sensitifitas & $105 \mathrm{~dB}$ \\
\hline
\end{tabular}

Untuk tegangan, modul ini cukup fleksibel dan dapat bekerja pada rentang tegangan 3-12V sehingga dapat dengan mudah digunakan pada tegangan $5 \mathrm{~V}$ sesuai dengan yang digunakan oleh arduino pada umumnya. Anda dapat menggunakan tegangan yang lebih tinggi jika ingin meningkatkan jangkauan modul ini, tentunya dengan tambahan beberapa komponen diskrit agar tidak merusak arduino yang Anda gunakan. [7]

\subsection{Pengujian}

Pengujian dilakukan untuk mengetahui apakah alat yang sudah di rancang telah memenuhi kebutuhan fungsional yang harapkan penulis. Pengujian packet loss dihitung dalam waktu 5 menit.

Tabel 3. Hasil Pengujian Berdasarkan Kebutuhan Fungsional

\begin{tabular}{cccccc}
\hline \multirow{2}{*}{ No } & Kebutuhan & \multicolumn{3}{c}{ Pengujian } & Status \\
\cline { 3 - 5 } & Fungsional & Jarak & Waktu rata-rata & Packet loss & \\
\hline 1 & Siaga I & $20 \mathrm{~m}$ & 0.47 detik. & $96.7 \%$ berhasil & Berhasil \\
\hline 2 & Siaga II & $20 \mathrm{~m}$ & 0.26 detik & $97.8 \%$ berhasil & Berhasil \\
\hline 3 & Siaga III & $20 \mathrm{~m}$ & 0.68 detik & $95.9 \%$ berhasil & Berhasil \\
\hline 4 & Siaga IV & $20 \mathrm{~m}$ & 0.35 detik & $98.3 \%$ berhasil & Berhasil \\
\hline 5 & Siaga I & $40 \mathrm{~m}$ & 0.75 detik & $97.0 \%$ berhasil & Berhasil \\
\hline 6 & Siaga II & $40 \mathrm{~m}$ & 0.66 detik & $96.5 \%$ berhasil & Berhasil \\
\hline 7 & Siaga III & $40 \mathrm{~m}$ & 0.74 detik & $96.3 \%$ berhasil & Berhasil \\
\hline 8 & Siaga IV & $40 \mathrm{~m}$ & 0.96 detik & $97.9 \%$ berhasil & Berhasil \\
\hline 9 & Siaga I & $60 \mathrm{~m}$ & 0.81 detik & $97.3 \%$ berhasil & Berhasil \\
\hline 10 & Siaga II & $60 \mathrm{~m}$ & 0.85 detik & $97.5 \%$ berhasil & Berhasil \\
\hline 11 & Siaga III & $60 \mathrm{~m}$ & 0.64 detik & $95.6 \%$ berhasil & Berhasil \\
\hline 12 & Siaga IV & $60 \mathrm{~m}$ & 0.92 detik & $97.2 \%$ berhasil & Berhasil \\
\hline 13 & Siaga I & $80 \mathrm{~m}$ & 0.85 detik & $95.9 \%$ berhasil & Berhasil \\
\hline 14 & Siaga II & $80 \mathrm{~m}$ & 1.12 detik & $95.2 \%$ berhasil & Berhasil \\
\hline 15 & Siaga III & $80 \mathrm{~m}$ & 0.97 detik & $95.8 \%$ berhasil & Berhasil \\
\hline 16 & Siaga IV & $80 \mathrm{~m}$ & 1.24 detik & $94.5 \%$ berhasil & Berhasil \\
\hline
\end{tabular}




\begin{tabular}{cccccc}
\hline \multirow{2}{*}{ No } & Kebutuhan & \multicolumn{3}{c}{ Pengujian } & Status \\
\cline { 3 - 5 } & Fungsional & Jarak & Waktu rata-rata & Packet loss & \\
\hline 17 & Siaga I & $100 \mathrm{~m}$ & Gagal & Gagal & Gagal \\
\hline 18 & Siaga II & $100 \mathrm{~m}$ & Gagal & Gagal & Gagal \\
\hline 19 & Siaga III & $100 \mathrm{~m}$ & Gagal & Gagal & Gagal \\
\hline 20 & Siaga IV & $100 \mathrm{~m}$ & Gagal & Gagal & Gagal \\
\hline
\end{tabular}

Dari tabel 3 hasil pengujian bahwa menggunakan pengiriman pesan singkat menggunakan mudul RF $433 \mathrm{MHz}$ pada jarak $<=80$ meter informasi dapat terkirim dengan waktu delay rata-rata kurang dari 1 detik, dengan packet loss rata-rata diatas $97 \%$ yang artinya dari 100\% informasi yang dikirim dalam waktu masing-masing 5 menit hanya kurang lebih 3\% informasi tidak terkirim. Sedangkan pada jarak $>=100$ meter informasi tidak tersampaikan kepada alat penerima hal ini dikarenakan spesifikasi penggunaan antenna bawaan dari modul tersebut yang tidak maksimal. Hal ini dapat diatasi dengan mengganti antenna yang digunakan dengan antenna yang lebih baik lagi.

\section{KESIMPULAN}

Berdasarkan hasil pengujian, cara kerja dari penerapan modul RF 433MHz sebagai pengiriman data adalah membaca sensor ketinggian air kemudian mengirim informasi berdasarkan sensor melalui modul transmitter RF433MHz kemudian diterima oleh modul receiver RF $433 \mathrm{MHz}$ dan selanjutnya di proses oleh arduino kemudian menampilkan informasi ke LCD, untuk setatus "siaga IV" maka ada tambahan pemberitahuan melalui suara buzzer.

Pengiriman informasi status ketinggian air dengan menerapkan RF $433 \mathrm{MHz}$ sangat efektif karena tidak membutuhkan pulsa ataupun internet, sehingga masyarakat daerah aliran sungai bisa dengan cepat mendapatkan informasi ketinggian air apakah statusnya normal, siaga I, siaga II, siaga III atau siaga IV. Waktu pengiriman relatif cepat dengan persentase keberhasilan data terkirim rata-rata diatas 95\%, tetapi informasi masih terkirim sesuai dengan kebutuhan fungsional sistem.

\section{SARAN}

Saran untuk pengembangan sistem dari sistem ini adalah sebagai berikut:

1. Untuk dikembangkan lagi degan menggunakan banyak alat pengirim agar semakin banyak titik sungai yang ter monitoring ketinggian airnya.

2. Plat penerima diperbanyak agar bisa digunakan oleh banyak tempat monitoring di daerah aliran sungai.

3. Pada alat pengirim bisa ditambahkan panel surya agar tidak membutuhkan pergantian batre lagi dan bisa menghemat biaya untuk kebutuhan batre dari sistem tersebit.

4. menggunakan antenna yang lebih baik agar jarak pengiriman bisa maksimal.

\section{DAFTAR PUSTAKA}

[1] Arief Andy Soebroto, Imam Cholissodin, Randy Cahya Wihandika, Maria Tenika Frestantiya, Ziya El Arief, "Prediksi Tinggi Muka Air (TMA) Untuk Mendeteksi Dini Bencana Banjir Menggunakan SVR-TVWPSO," Jurnal Teknologi Informasi dan IImu Komputer (JTIIK), 2015.

[2] Muzakky, A., Nurhasi, A., Nurdiansyah, A., Wicaksana, G., Istiadi. (2018). Perancangan Sistem Deteksi Banjir Berbasis IoT. Conference on Innovation and Application of Science and Technology (CIASTECH 2018).

[3] Satria, D., Yana, S., Munadi, R., Syahreza, S. (2017). Sistem Peringatan Dini Banjir Berbasis Sms Gateway Dan Mikrokontroler Arduino Uno. Seminar Nasional II USM. Vol. 1, Oktober 2017, 78-82

[4] IK Khisan, "Konsep Rancangan Pendeteksi Banjir Jarak Jauh Memanfaatkan Fasilitas Pesan Singkat (SMS)," Jurnal Teknik Elektro Undip, 2011.

[5] A Sumarudin, M. Yani, WP. Putra, F. Amri, P. Paskal "Sistem Pemantauan dan Peringatan Dini Potensi Banjir Sungai Cimanuk Berbasis Internet of Things (IOT)" Prosiding Industrial Research Workshop and National Seminar, 2017.

[6] Slameto, A.A., Pramono, E., Arifin, Z., (2019). Sistem Pendeteksi Dini Bencana Banjir Menggunakan Teknik DTMF (Dual Tone Multiple Frequency). Jurnal Teknologi Informasi Vol. XIV Nomor 2 Juni 2019.

[7] Firmansyah, R., Bagaskara, S., Kurdyanto, R.A., Muizz, M.N.F. (2018). Penerapan Modul RF 433 dalam Pengukuran Intensitas Cahaya Menggunakan Sensor LDR Berbasis Arduino. Jurnal INAJEEE. Volume 01 Nomor 01 Tahun 2018, $0-37$. 